\title{
SALURAN PEMASARAN PEPAYA CALIFORNIA DI KELURAHAN URUG, KECAMATAN KAWALU KOTA TASIKMALAYA
}

\author{
Asya Utari ${ }^{1 *}$, Don Setia Umbara ${ }^{2}$, Budhi Wahyu Fitriadi ${ }^{3}$ \\ 1,2,3Prodi Agribisnis Fakultas Pertania Universitas Perjuangan Tasikmalaya, Jl. PETA No. 177 \\ Tasikmalaya 46115 Indonesia \\ Alamat korespondensi: asyautari@gmail.com
}

Naskah diterima: 20 Februari 2021 Direvisi: 27 Juli 2021 Disetujui terbit: 30 Agustus 2021

\begin{abstract}
The price of California papaya has always been a concern for farmers because of the problem of price fluctuations. The price of papaya at certain times drops due to several factors, including good weather which can lead to abundant production so that supply to the market increases, while demand tends to remain. The purpose of this study is to identify the marketing channels for California papayas in Urug Village and to analyze the efficiency of marketing of California papayas in Urug Village. The analytical tool in this study uses the analysis of the marketing margin approach, farmer's share analysis, and profit and cost ratio analysis. The results showed that there were four marketing channels. A relatively efficient marketing channel is marketing channel III (farmer retailer-consumer) because it has the smallest marketing margin, the largest farmer's share, and the ratio of profit to cost has a value of more than one.
\end{abstract}

Keywords: marketing channel, California papaya

\begin{abstract}
ABSTRAK
Harga buah pepaya California selalu menjadi kekuatiran bagi petani karena problema fluktuasi harga. Harga pepaya pada saat tertentu anjlok dikarenakan beberapa faktor, diantaranya cuaca yang baik bisa mengakibatkan produksi melimpah sehingga membuat pasokan ke pasar menjadi meningkat, sedangkan permintaan cenderung tetap. Tujuan penelitian ini yaitu mengidentifikasi saluran pemasaran pepaya California di Kelurahan Urug dan menganalisis efisiensi pemasaran pepaya California di Kelurahan Urug. Alat analisis dalam penelitian ini menggunakan analisis pendekatan marjin pemasaran, analisis farmer's share, dan analisis rasio keuntungan dan biaya. Hasil penelitian menunjukan bahwa terdapat empat saluran pemasaran. Saluran pemasaran yang relatif efisien adalah saluran pemasaran III (petani - pedagang pengecer - konsumen) karena memiliki marjin pemasaran terkecil, farmer's share paling besar, dan rasio keuntungan terhadap biaya memiliki nilai lebih dari satu.
\end{abstract}

Kata kunci: saluran pemasaran, pepaya California

\section{PENDAHULUAN}

Pepaya merupakan salah satu buah yang banyak diminati masyarakat baik dalam negeri maupun luar negeri dengan nama latin Carica papaya L. Produksi buah pepaya tahunan di Indonesia cukup meningkat dari tahun ke tahunnya. (BPS Indonesia, 2019). Buah pepaya selain dagingnya manis harga buah pepaya juga sangat ekonomis, rata-rata harga pertumbuhan pepaya di tingkat produsen 
lebih kecil dari rata-rata pertumbuhan harga papaya yang sampai di tingkat konsumen, kenaikan harga papaya di tingkat konsumen tidak diikuti kenaikan harga yang cukup adil di tingkat produsen (Satria et al., 2018)

Tabel 1. Produksi Buah Pepaya per Triwulan

\begin{tabular}{|c|c|}
\hline Tahun & $\begin{array}{c}\text { Produksi buah pepaya } \\
\text { tahunan (TON)/Triwulan }\end{array}$ \\
\hline 2014 & 218968 \\
\hline 2015 & 227426 \\
\hline 2016 & 218501 \\
\hline 2017 & 232734 \\
\hline 2018 & 244427 \\
\hline
\end{tabular}

Penghasil buah pepaya tentunya sangat banyak di jumpai di Provinsi Jawa Barat salah satunya sentra penghasil buah pepaya adalah Kota Tasikmalaya dikarenakan kondisi iklimnya sangat cocok untuk budidaya buah pepaya. Produksi buah pepaya di Tasikmalaya pada tahun 2018 sebesar 62,227 kwintal, hal ini menunjukan bahwa kota Tasikmalaya memiliki potensi produksi buah pepaya yang besar di Jawa Barat (BPS Provinsi Jawa Barat, 2018), dan Petani pepaya tentunya banyak di jumpai di Kota Tasikmalaya, salah satu kecamatan penghasil buah pepaya dan memiliki potensi yang besar untuk pengembangan budidaya pep aya yaitu kecamatan Kawalu, kelurahan Urug. Produksi pepaya di kelurahan urug paling besar di dominasi oleh pepaya variates california di bandingkan dengan pepaya jenis yang lainnya atau bisa di katakan sudah jarang menemukan jenis pepaya yang lain selain california (Astriana \& Nurcahyo, 2017).

Harga buah pepaya California selalu menjadi kekuatiran bagi petani karena problema fluktuasi harga. Saluran pemasaran merupakan suatu jalan yang diikuti dalam mengalihkan pemilikan secara langsung atau tidak langsung atas suatu produk dan produk akan beralih dari produsen hingga ke konsumen akhir (Permana et al., 2020). Berdasarkan hal tersebut, peneliti ingin mengetahui bagaimana saluran pemasaran di Keluraha Urug? dan Bagaimana efisiensi pemasaran buah papaya di Kelurahan Urug?

\section{METODE PENELITIAN}

Metode yang digunakan pada penelitian ini menggunakan metode deskriptif kualitatif dan kuantitatif dengan teknik penelitian yang digunakan adalah metode survey. Penelitian ini dilakukan di Kelurahan Urug, Kecamatan Kawalu, Kota Tasikmalaya. 
Teknik penentuan sampel dalam penelitian ini dipilih secara sengaja (purporsive), Jumlah populasi pada penelitian ini yaitu 300 orang petani karena hampir seluruh warga Kelurahan Urug bertani. Menurut Arikunto. S (2013), sampel adalah sebagian atau wakil dari populasi yang akan diteliti. Menurut Imran (2017), salah satu metode yang digunakan untuk menentukan jumlah sampel adalah menggunakan rumus slovin. Jumlah populasi dalam penelitian saluran pemasaran pepaya California di Kelurahan Urug sebanyak 300 orang petani. Berdasarkan pada rumus slovin maka akan diperoleh sampel sebagai berikut :

$$
n=\frac{300}{1+300(0,1)^{2}}=\frac{300}{1+3}-75
$$

Berdasarkan pada perhitungan rumus slovin maka diperoleh sampel yang akan menjadi responden dalam penelitian yaitu sebanyak 75 responden. Alat analisis yang digunakan dalam penelitian ini menggunakan analisis kualitatif dan kuantitatif. Pengolahan dengan analisis kualitatif dilakukan dengan mendeskripsikan saluran pemasaran dan lembaga pemasaran yang ada. Sedangkan analisis kuantitatif dilakukan untuk menganalisis efisiensi pemasaran berdasarkan pendekatan marjin pemasaran, farmer's share, dan rasio keuntungan dan biaya.

Menurut Yulita et al., (2016) model marjin pemasaran dihitung dengan menggunakan rumus sebagai berikut:

$$
M P=P r-P f .
$$

Dimana:

MP : Marjin Pemasaran

Pr : Harga ditingkat konsumen (Rp/buah)

Pf : Harga ditingkat produsen (Rp/buah)

Menurut Sutarno (2014) bagian yang di terima petani dapat di hitung dengan rumus farmer share sebagai berikut:

$$
F s=\frac{P f}{P r} \times 100 \% \ldots \ldots .(2)
$$

Dimana:

Fs = Bagian harga yang diterima petani

Pf = Harga papaya ditingkat petani

$\operatorname{Pr}=$ Harga papaya ditingkat konsumen

Rasio keuntungan dan biaya dilakukan untuk mengetahui besarnya keuntungan yang diterima atas biaya yang dikeluarkan pada lembaga pemasaran, Adapun rumus untuk menghitung keuntungan dan biaya adalah: 


$$
\text { Rasio keuntungan dan biaya }(\%)=\frac{\pi i(\text { keuntungan })}{C i(\text { biaya pemasaran })} \times 100 \%
$$

Menurut Pratama et al, (2020) jika nilai rasio keuntungan terhadap biaya positif dapat disimpulkan bahwa aktivitas pemasaran tersebut relatif menguntungkan.

\section{HASIL DAN PEMBAHASAN}

\section{Karakteristik Wilayah}

Kelurahan Urug dikenal sebagai salah satu sentra pertanian yang berada di ketinggian \pm 300 mdpl, dengan luas wilayah sebesar 909,390 ha. Luas lahan pertanian di kelurahan urug sebesar 306,209 ha, dan luas pesawahan sebesar 90,7 ha. Wilayah ini memiliki potensi sumber daya alam yang melimpah, terlihat dari tanaman yang tumbuh mulai dari buah-buahan sampai sayur-sayuran (BPS Kota Tasikmalaya, 2019).

\section{Karakteristik Petani Responden}

Umur Responden

\begin{tabular}{|c|c|c|}
\hline $\begin{array}{c}\text { Kelompok } \\
\text { Umur }\end{array}$ & $\begin{array}{c}\text { Responde } \\
\mathrm{n}\end{array}$ & $\begin{array}{c}\text { Persentas } \\
\mathrm{e}\end{array}$ \\
\hline <30 Tahun & 25 & 33,34 \\
\hline 31-40 Tahun & 21 & 28,00 \\
\hline 41-50 Tahun & 20 & 26,67 \\
\hline 51-60 Tahun & 5 & 6,67 \\
\hline >61 Tahun & 4 & 5,34 \\
\hline \multicolumn{2}{|c|}{ Jumlah } & 100,00 \\
\hline
\end{tabular}

Hasil dari wawancara menjelaskan bahwa karakteristik petani responden yang didapat berbeda beda, mulai dari umur responden, tingkat pendidikan, lama bertani, dan luas kebun yang di garap.Selain umur pendidikan formal juga menjadi salah satu yang mendasari keputusan petani dalam proses keputusan penjualan.

Pendidikan Responden

\begin{tabular}{|l|l|l|}
\hline $\begin{array}{l}\text { Tingkat } \\
\text { Pendidikan }\end{array}$ & $\begin{array}{l}\text { Jumlah } \\
\text { Responden } \\
\text { (orang) }\end{array}$ & $\begin{array}{l}\text { Persentase } \\
\text { (persen) }\end{array}$ \\
\hline SD & 63 & 84,00 \\
\hline SMP & 12 & 16,00 \\
\hline SMA & - & 0 \\
\hline Jumlah & 100,00 \\
\hline
\end{tabular}

Tingkat pendidikan yang kurang memadai juga dikarenakan beberapa faktor ekonomi petani yang kurang mampu untuk melanjutkan pendidikannya (Mandala et al., 2016). Rendahnya tingkat pendidikan petani nantinya akan menghambat petani dalam cara berpikir dan menyerap teknologi.

\section{Lama Bertani}

$$
\text { Karakteristik petani responden }
$$
berdasarkan lama bertani kurang dari 15 tahun sampai lebih dari 35 tahun. Petani responden di kelurahan urug berdasarkan lama Bertani kebanyakn kurang dari 15 tahun. Pengalaman berusahatani bisa mempengaruhi sikap 
dalam menghadapi permasalahan yang dihadapinya. Dari pengalaman usahatani petani dapat bisa mengatasi masalahnya dengan cara yang lebih baik.Semakin banyak pengalaman yang dapat diperoleh petani, maka keterampilan dan kemampuan mereka terhadap usahatani tersebut semakin tinggi.

Luas Kebun

Petani responden dengan luas kebun $2.500-5.000 \mathrm{~m}^{2}$ yang paling banyak yaitu sebanyak 36 orang dengan persentase 48,00 persen. Kebun yang yang dimiliki petani responden sebagian besar milik petani sendiri, dan ada juga petani yang hanya menggarap kebun orang lain.

\section{Karakteristik Lembaga Pemasaran}

Lembaga pemasaran yang dijadikan responden sebanyak 5 orang yang diambil dengan mengikuti aliran produk mulai dari petani responden sampai ke pengecer. Lembaga pemasaran yang ada langsung mengunjungi petani, sehingga petani tidak mengeluarkan biaya apapun. Lembaga pemasaran ini membeli langsung dari petani dan mendistribusikan baik secara langsung kepada konsumen atau pedagang di luar maupun di dalam kota. Lembaga pemasaran di Kelurahan Urug terdiri dari pedagang pengumpul, pedagang besar, dan pedagang pengecer.

Tabel 1. Karakteristik Lembaga Pemasar di Kelurahan Urug

\begin{tabular}{|c|c|c|c|c|c|}
\hline \multirow[t]{2}{*}{ No } & \multirow[t]{2}{*}{ Uraian } & \multirow{2}{*}{$\begin{array}{l}\text { Umur } \\
\text { (Tahun) }\end{array}$} & Pendidikan & \multirow{2}{*}{$\begin{array}{c}\text { Pengalaman } \\
\text { berdagang } \\
\text { (Tahun) }\end{array}$} & \multirow{2}{*}{$\begin{array}{l}\text { Jumlah } \\
\text { (orang) }\end{array}$} \\
\hline & & & SD SMP & & \\
\hline \multirow[t]{2}{*}{1.} & Pedagang Pengecer & 47 & 1 & 6 & 2 \\
\hline & & 52 & 1 & 5 & \\
\hline \multirow[t]{2}{*}{2.} & Pedagang Pengumpul & 32 & 1 & 3 & 2 \\
\hline & & 43 & 1 & 9 & \\
\hline 3. & Pedagang Besar & 45 & 1 & 16 & 1 \\
\hline
\end{tabular}

Sumber: Data Primer, 2020 (diolah)

\begin{tabular}{|c|c|}
\hline \multirow{2}{*}{$\begin{array}{lrr}\text { Analisis Saluran dan } & \text { Lembaga } \\
\text { Pemasaran } & & \\
\text { Pengumpulan } & \text { data } & \text { untuk }\end{array}$} & \\
\hline & \\
\hline mengetahui berbaga & \\
\hline \multirow{2}{*}{$\begin{array}{l}\text { pepaya yang digunakan, diperoleh } \\
\text { dengan cara penelusuran pola saluran }\end{array}$} & $\begin{array}{l}\text { hasil penelitian yang telah dilaksanakan } \\
\text { mengenai pola saluran pemasaran pepaya } \\
\text { California di kelurahan Urug, kecamatan }\end{array}$ \\
\hline & Kawalu, Kota Tasikmalaya terdap \\
\hline
\end{tabular}




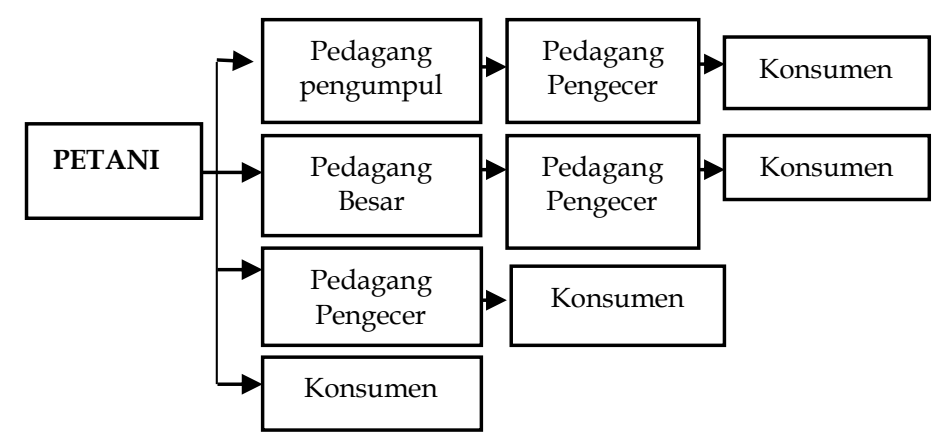

Gambar 1. Pola Saluran Pemasaran Pepaya California di Kelurahan Urug

Pola saluran tersebut adalah:

1. Saluran I:

petani-pedagang pengumpulpedagang pengecer konsumen akhir. Petani responden yang menyalurkan pepaya pada saluran pemasaran ini yaitu sebanyak 33 orang atau 44,00 persen dari total keseluruhan.

2. Saluran II:

Petani - Pedagang besar - pedagang pengecer - konsumen akhir. Petani responden yang menyalurkan pepaya california kepada pedagang besar yaitu sebanyak 33 orang atau 44,00 persen dari total keseluruhan petani responden.

3. Saluran III:

Ppetani - pedagang pengecer konsumen akhir. Petani responden pada saluran pemasaran ini sebanyak 7 orang atau 9,39 persen dari total keseluruhan petani responden.

4. Saluran IV: petani - konsumen akhir. Petani responden yang menyalurkan pepaya california di saluran pemasaran ini sebanyak 2 orang atau 4,60 persen dari total keseluruhan petani responden.

\section{Analisin Fungsi Pemasaran}

Fungsi pemasaran merupakan sejumlah kegiatan yang dilakukan oleh lembaga pemasaran untuk kelancaran dalam kegiatan pemasaran. Fungsi pemasaran yang dilakukan oleh setiap lembaga pemasaran bermacam-macam. Fungsi yang pertama adalah fungsi pertukaran yaitu proses pemindahan kepemilikan barang atau jasa dari produsen ke konsumen yaitu berupa pembelian dan pemasaran. Fungsi yang kedua adalah Fungsi fisik yaitu kegiatan yang melibatkan barang atau jasa tersebut dalam bentuk kegunaan waktu, dan tempat sehingga menjadi fungsi pengemasan, penyimpanan dan 
pengagkutan. Fungsi yang ketiga adalah fungsi fasilitas yaitu kegiatan yang dilakukan oleh lembaga pemasaran sehingga memperlancar kegiatan pemasaran barang atau jasa.

Fungsi pemasaran berupa fungsi pertukaran yang dilakukan oleh petani responden adalah pemasaran. Fungsi pertukaran yang dilakukan lembaga pemasaran responden dalam penelitian adalah pembelian dan pemasaran. Fungsi Fisik pada penelitian ini meliputi biaya transportasi, pengangkutan, sortir, bongkar muat, penyimpanan, dan pengemasan. Fungsi fasilitas dalam penelitian ini mencakup pembiayaan, penanggung resiko, dan informasi harga pasar.

Tabel 3. Rincian biaya pemasaran papaya California di Kelurahan Urug, Kecamatan Kawalu, Kota Tasikmalaya

\begin{tabular}{lcccc}
\hline Jenis Biaya Setiap Lembaga & \multicolumn{4}{c}{ Jumlah Biaya Rata-rata (Rp/kg) setiap Saluran Pemasaran } \\
\cline { 2 - 5 } Pemasaran & I & II & III & IV \\
\hline Pedagang Pengecer & 116,88 & & & \\
Biaya Pengemasan & & 141,10 & 79,36 & 136,36 \\
Biaya transportasi & & & 79,36 & \\
Biaya penyimpanan & & & 238,09 & \\
\hline Pedagang Pengumpul & & & \\
Biaya pemanenan & 86,58 & & \\
Biaya Transportasi & 38,96 & & \\
\hline Pedagang Besar & & & \\
Biaya pengangkutan & & 404,29 & \\
Biaya penyimpanan & & 42,94 & \\
Biaya sortir & & 67,48 & \\
Biaya transportasi & & 55,21 & \\
Biaya bongkarmuat & & 46,01 & \\
\hline
\end{tabular}

Sumber : Data Primer, 2020 (diolah

\section{Analisis Marjin Pemasaran}

Analisis marjin pemasaran merupakan indikator dalam melihat efisiensi pemasaran. Marjin pemasaran merupakan hasil pengurangan harga di tingkat petani dengan harga ditingkat konsumen akhir dan dihitung mulai dari harga ditingkat petani, pedagang pengumpul, pedagang besar, pedagang pengecer dan konsumen akhir (Pradika et al., 2013). Marjin yang paling tinggi terdapat pada saluran pemasaran II yaitu petani pedagang besar - pedagang pengecer - konsumen sebesar Rp. $4.000 / \mathrm{kg}$. Biaya pemasaran yang cukup besar disebabkan karena pedagang besar menjalankan fungsi-fungsi pemasaran mulai dari pengangkutan, penyimpanan, sortir, grading dan bongkar muat. Marjin pemasaran yang paling rendah terdapat pada saluran pemasaran III yaitu sebesar 
Rp. $2.500 / \mathrm{kg}$. Tinggi rendahnya nilai proses pemasaran dan keuntungan marjin pemasaran dipengaruhi oleh biaya-biaya yang dikeluarkan dalam yang diperoleh oleh masing-masing lembaga pemasaran.

Tabel 4. Marjin Pemasaran pada setiap saluran pemasaran di Kelurahan Urug

\begin{tabular}{|c|c|c|c|c|c|}
\hline \multirow[t]{2}{*}{ No } & \multirow{2}{*}{ Lembaga Pemasaran } & \multicolumn{4}{|c|}{ Saluran Pemasaran Rp/Kg } \\
\hline & & 1 & 2 & 3 & 4 \\
\hline \multirow[t]{4}{*}{1} & Pedagang Pengumpul & & & & \\
\hline & Harga Beli & 2.200 & & & \\
\hline & Harga Jual & 3.500 & & & \\
\hline & Marjin & 1.300 & & & \\
\hline \multirow[t]{4}{*}{2} & Pedagang Besar & & & & \\
\hline & Harga Beli & & 3.000 & & \\
\hline & Harga Jual & & 5.500 & & \\
\hline & Marjin & & 2.500 & & \\
\hline \multirow[t]{5}{*}{3} & Pedagang Pengecer & & & & \\
\hline & $\begin{array}{l}\text { Harga Beli } \\
\end{array}$ & 3.500 & 5.500 & 2.000 & \\
\hline & Harga Jual & 5.500 & 7.000 & 4.500 & 4.500 \\
\hline & Marjin & 2.000 & 1.500 & 2.500 & - \\
\hline & Total Marjin & 3.300 & 4.000 & 2.500 & - \\
\hline
\end{tabular}

Sumber: Data Primer (2020)

\section{Analisis Farmer's Share}

Tabel 5. Farmer's Share pada saluran pemasaran di Kelurahan Urug

\begin{tabular}{lcccc}
\hline Saluran Pemasaran & Volume (Kg) & $\begin{array}{c}\text { Harga } \\
\text { ditingkat } \\
\text { Petani } \\
(\mathrm{Rp} / \mathrm{Kg})\end{array}$ & $\begin{array}{c}\text { Harga } \\
\text { ditingkat } \\
\text { Konsumen } \\
\text { akhir } \\
(\mathrm{Rp} / \mathrm{Kg})\end{array}$ & $\begin{array}{c}\text { Farmer's } \\
\text { share (\%) }\end{array}$ \\
\hline Saluran Pemasaran I & 11550 & 2.200 & 5.500 & 40.00 \\
Saluran Pemasaran II & 8150 & 3.000 & 7.000 & 42.85 \\
Saluran Pemasaran III & 3150 & 2.000 & 4.500 & 44.44 \\
Saluran Pemasaran IV & 1100 & 4.500 & 4.500 & 100 \\
\hline
\end{tabular}

Farmer's share merupakan perbandingan antara harga ditingkat petani dengan harga yang dibayarkan oleh konsumen akhir. Farmer's share merupakan indikator efisiensi operasional yang menunjukan bagian yang diterima petani dari aktivitas pemasaran (Iswahyudi \& Sutiyana, 2019).

Farmer's share tertinggi terdapat pada saluran pemasaran IV yaitu sebesar 100 persen. Saluran pemasaran IV tidak dapat dijadikan sebagai pembanding dalam 
analisis farmer's share untuk saluran pemasaran lainnya karena saluran pemasaran bersifat langsung tidak melalui lembaga pemasaran lainnya. farmer's share yang dapat dibandingkan dengan saluran pemasaran lain yang tertinggi yaitu saluran pemasarn ke III sebesar $44.44 \%$ hal tersebut disebabkan karena harga jual petani dengan harga jual pedagang pengecer ke konsumen tidak terlalu besar

Biaya-biaya yang dikeluarkan pada saluran pemasaran III dalam menjalankan fungsi-fungsi pemasaran dan keuntungan yang diambil oleh pedagang pengecer tidak terlalu besar dibandingkan saluran pemasaran I dan II. Saluran pemasaran II mempunyai nilai farmer's share sebesar 42.85 $\%$, harga lebih tinggi yang dibandingkan harga yang diterima oleh petani lain. Petani - pepaya california lebih banyak menjual hasil panennya pada saluran pemasaran I yang mempunyai nilai farmer's share sebesar $40.00 \%$ hal tersebut mengindikasikan bahwa saluran pemasaran yang digunakan oleh petani belum memberikan imbalan yang baik terhadap harga yang dibayar konsumen akhir (Yani \& Hermanto, 2019).

\section{Analisis Rasio Keuntungan dan Biaya}

Tabel 6. Rasio Keuntungan terhadap Biaya pada Saluran Pemasaran Pepaya California di Kelurahan Urug

\begin{tabular}{|c|c|c|c|}
\hline Lembaga Pemasaran & $\begin{array}{l}\text { Keuntungan }(\pi i) \\
(\mathrm{Rp} / \mathrm{Kg})\end{array}$ & $\begin{array}{c}\text { Biaya (Ci) } \\
(\mathrm{Rp} / \mathrm{Kg})\end{array}$ & $\begin{array}{c}\text { Rasio Keuntungan dan } \\
\text { Biaya }(\pi i / \mathrm{C} i)\end{array}$ \\
\hline \multicolumn{4}{|c|}{ Saluran Pemasaran I } \\
\hline $\begin{array}{l}\text { Pedagang } \\
\text { Pengumpul } \\
\text { Pedagang Besar }\end{array}$ & 1175 & 125,54 & 9,3 \\
\hline Pedagang Pengecer & 1883 & 116,88 & 16,1 \\
\hline \multicolumn{4}{|c|}{ Saluran Pemasaran II } \\
\hline \multicolumn{3}{|l|}{ Pedagang } & Pengumpul \\
\hline Pedagang Besar & 2184 & 315,95 & 6,9 \\
\hline Pedagang Pengecer & 1358 & 141,10 & 9,6 \\
\hline \multicolumn{4}{|c|}{ Saluran Pemasaran III } \\
\hline \multicolumn{4}{|l|}{$\begin{array}{l}\text { Pedagang } \\
\text { Pengumpul } \\
\text { Pedagang Besar }\end{array}$} \\
\hline Pedagang Pengecer & 2103 & 396,82 & 5,3 \\
\hline \multicolumn{4}{|c|}{ Saluran Pemasaran IV } \\
\hline \multicolumn{4}{|l|}{$\begin{array}{l}\text { Pedagang } \\
\text { Pengumpul } \\
\text { Pedagang Besar }\end{array}$} \\
\hline Pedagang Pengecer & 4363 & 136,36 & 32,1 \\
\hline
\end{tabular}


Sumber: Data Primer (2020)

Rasio keuntungan terhadap biaya yaitu besarnya biaya yang diterima atas biaya yang dikeluarkan pada lembaga pemasaran. Keuntungan pemasaran dapat diperoleh dari penerimaan dikurangi biaya pemasaran. Biaya pemasaran pepaya california adalah biaya yang dikeluarkan dalam proses penyaluran pepaya california (Arbi et al., 2018). Berikut rasio keuntungan terhadap biaya pada saluran pemasaran papaya California di Kelurahan Urug dapat dilihat pada table 6 .

Besarnya keuntungan yang diperoleh karena petani menjual langsung ke konsumen akhir sehingga keuntungan lebih besar dibandingkan jika petani menjual ke lembaga pemasaran, Hal tersebut keuntungan yang diambil oleh lembaga pemasaran tidak terlalu besar.

\section{Efisiensi Pemasaran}

Tujuan akhir yang ingin dicapai dalam proses pemasaran adalah efisiensi sistem pemasaran yang memberikan kepuasan kepada seluruh pelaku yang terlibat dalam pemasaran. Efisiensi pemasaran dapat diukur dengan membandingkan nilai marjin pemasaran, farmer's share, dan rasio keuntungan terhadap biaya. Berdasarkan hasil penelitian pada pemasaran pepaya California di Kelurahan Urug, Kecamatan Kawalu, Kota Tasikmalaya nilai dari indikator efisiensi pemasaran pepaya California dapat dilihat pada tabel di bawah ini:

Tabel 7. Nilai Efisiensi Pemasaran pada Saluran Pemasaran di Kelurahan Urug

\begin{tabular}{ccccccc}
\hline $\begin{array}{c}\text { Saluran } \\
\text { Pemasaran }\end{array}$ & $\begin{array}{c}\text { Volume } \\
(\mathrm{Kg})\end{array}$ & $\begin{array}{c}\text { Marjin } \\
\text { Pemasaran } \\
(\mathrm{Rp} / \mathrm{kg})\end{array}$ & $\begin{array}{c}\text { Keuntungan } \\
\text { Pemasaran } \\
(\mathrm{Rp} / \mathrm{kg})\end{array}$ & $\begin{array}{c}\text { Biaya } \\
\text { Pemasaran } \\
(\mathrm{Rp} / \mathrm{kg})\end{array}$ & $\begin{array}{c}\text { Farmer's } \\
\text { share } \\
(\%)\end{array}$ & $\begin{array}{c}\text { Rasio } \\
(\pi i / \mathrm{C} i)\end{array}$ \\
\hline $\begin{array}{c}\text { Saluran } \\
\text { Pemasaran I } \\
\text { Saluran }\end{array}$ & 11550 & 3.300 & 3058 & 242,42 & 40,00 & 25,4 \\
$\begin{array}{c}\text { Pemasaran II } \\
\text { Saluran }\end{array}$ & 8150 & 4.000 & 3542 & 469,32 & 42,85 & 16,5 \\
$\begin{array}{c}\text { Pemasaran III } \\
\text { Saluran }\end{array}$ & 3150 & 2.500 & 2103 & 396,82 & 44,44 & 5,3 \\
Pemasaran IV & 1100 & - & 4363 & 136,36 & 100 & 32,1 \\
\hline
\end{tabular}

Sumber: Data Primer (2020)

Hasil analisis saluran pemasaran IV memiliki rasio keuntungan terhadap biaya yang paling besar yaitu 32,1 dan farmer's share 100 persen, akan tetapi saluran pemasaran IV tidak dijadikan pembanding dalam efisiensi saluran pemasaran karena petani menjual hasil panennya langsung kepada konsumen akhir tidak melalui 
lembaga pemasaran. Efisiensi pemasaran dapat dilihat dari nilai marjin pemasaran terendah, farmer's share terbesar, dan rasio keuntungan terhadap biaya yang merata (Faisal, 2015).

Saluran pemasaran yang relatif efisien terdapat pada saluran pemasaran III karena memiliki marjin pemasaran kecil, farmer's share yang paling tinggi, dan rasio keuntungan terhadap biaya yang bernilai positif. Dari sisi konsumen akhir pun tidak merasa dirugikan karena memperoleh harga yang tidak terlalu mahal. Rasio keuntungan terhadap biaya dan total keuntungan saluran pemasaran ini paling kecil dibandingkan saluran pemasaran yang lain. Hal tersebut dikarenakan harga jual yang ditetapkan oleh lembaga pemasaran tidak terlalu besar dan keuntungan yang diambil hanya dinikmati pedagang pengecer saja. Lembaga pemasaran yang terlibat pada saluran pemasaran III hanya petani dan pedagang pengecer saja sehingga memutus mata rantai pedagang sebelumnya yaitu pedagang pengumpul dan pedagang besar.

\section{KESIMPULAN DAN SARAN}

\section{Kesimpulan}

Berdasarkan hasil penelitian dan pembahasan, maka dapat ditarik kesimpulan sebagai berikut:
1. Saluran pemasaran pepaya california di Kelurahan Urug, Kecamatan Kawalu, Kota Tasikmalaya terbagi menjadi empat pola saluran pemasaran yaitu:

a. Saluran Pemasaran I: petani menjual kepada pedagang pengumpul, kemudian dijual kepada pedagang pengecer, dari pedagang pengecer ke konsumen akhir.

b. Saluran Pemasaran II: petani menjual kepada pedagang besar, kemudian dijual kepada pedagang pengecer, dai pedagang pengecer ke konsumen akhir.

c. Saluran Pemasaran III: petani menjual kepada pedagang pengecer, kemudian dari pedagang pengecer ke konsumen akhir.

d. Saluran Pemasaran IV: petani menjual langsung ke konsumen akhir.

2. Saluran pemasaran yang efisien terdapat pada saluran pemasaran III (petani pedagang pengecer - konsumen) karena memiliki marjin pemasaran yang kecil yaitu sebesar Rp. 2.500, farmer's share paling tinggi sebesar $44.44 \%$, dan rasio keuntungan terhadap biaya bernilai positif yaitu 5,3 rupiah.

\section{Saran}


Saluran pemasaran yang efisien terdapat pada saluran pemasaran III (petani - pedagang pengecer - konsumen). Oleh sebab itu sebaiknya petani menjual pepaya california melalui saluran pemasaran III karena memiliki farmer's share yang paling tinggi diantara saluran pemasaran lain yang dibandingkan.

\section{DAFTAR PUSTAKA}

Arbi, M., Thirtawati, \& Junaidi, Y. (2018). Analisis Saluran Dan Tingkat Efisiensi Pemasaran Beras Semi Organik Di Kecamatan Rambutan Kabupaten Banyuasin. JSEP (Journal of Social and Agricultural Economics), 11(1), 22. https://doi.org/10.19184/jsep.v11i3. 7151

Arikunto. S. (2013). Prosedur Penelitian Suatu Pendekatan Praktik. Reinkacipta.

Astriana, S., \& Nurcahyo, I. (2017). Pemanfaatan Potensi Pepaya Sebagai Upaya Peningkatan Pendapatan Masyarakat Desa Tambak Kecamatan Mojosongo Kabupaten Boyolali. Jurnal Kewirausahaan Dan Bisnis, 20(11). https://doi.org/10.20961/jkb.v20i11. 13986

BPS Indonesia. (2019). Perkembangan RataRata Harga Produsen dan Konsumen Pepaya Menurut Provinsi Tahun 20142018.

BPS Kota Tasikmalaya. (2019). Kota Tasikmalaya Dalam Angka 2018. Tasikmalaya

BPS Provinsi Jawa Barat. (2018). Produksi Buah Pepaya Tahun 2018.

Faisal, H. (2015). Analisis Pendapatan Usahatani Dan Saluran Pemasaran Pepaya (Carica Papaya L) Di
Kabupaten Tulungagung (Studi kasus di Desa Bangoan, Kecamatan Kedungwaru, Kabupaten Tulungagung ). Agribis, 11(13), 12-28.

Imran, H. A. (2017). Peran Sampling dan Distribusi Data Dalam Penelitian Komunikasi Pendekatan Kuantitatif. Studi Komunikasi Dan Media, 21(1), 111-126.

Iswahyudi, \& Sutiyana. (2019). Pola Saluran Pemasaran Dan Farmer' S Share Jambu Air CV Camplong. Jurnal Hexagro, 3(2), 33-38.

Mandala, P., Maharani, E., \& Muardi, D. (2016). Analisis Pemasaran Jeruk Siam Di Desa Limau Manis Kecamatan Kampar Kabupaten Kampar. JOM Faperta UR, 3(2), 1-14.

Permana, H., Noor, T. I., \& Isyanto, A. Y. (2020). Analisis Saluran Pemasaran Pepaya California (Suatu Kasus di Desa Sukajaya Kecamatan Pamarican Kabupaten Ciamis). Jurnal Ilmiah Mahasiswa AGROINFO GALUH, 7(1), 7-13.

Pradika, A., Hasyim, A. I., \& Soelaiman, A. (2013). Analisis Efisiensi Pemasaran Ubi Jalar di Kabupaten Lampung Tengah. Jurna JIA, 1(1), 25-35.

Satria, Zakiah, \& Romano. (2018). Jurnal Ilmiah Mahasiswa Pertanian Unsyiah Volume 2, Nomor 1, November 2016. Jurnal Ilmiah Mahasiswa Pertanian Unsyiah, 3(4), 227-236.

Yani, F., \& Hermanto, B. (2019). Analisis Pendapatan Usahatani Pepaya California (Carica papaya L.) (Studi kasus : Desa Jaharun A Kecamatan Galang dan Desa Galang Suka,Kecamatan Galang, Kabupaten Deli Serdang). Prosiding Seminar Nasional Dan Ekspo Hasil Penelitian Dan Pangabdian Masyarakat, 462-466. 
Yulita, D., Murad, \& Sukmawaty. (2016). Analisis Energi Panas Pada Proses Pengeringan Manisan Pepaya (Carica Papaya L.) Menggunakan Alat
Pengering Tipe Rak. Jurnal Ilmiah Rekayasa Pertanian Dan Biosistem, 4(1), 192-199. 